\title{
IV
}

\section{O CURRÍCULO NA EDUCAÇÃO DE JOVENS E ADULTOS: ANÁLISE DA EXPERIÊNCIA DO MUNICÍPIO DE ITABORAÍ*}

\author{
Adriana Barbosa da Silva
}

A construção deste trabalho permitiu identificar que Currículo e Educação de Jovens e Adultos (EJA) são campos com sentidos em disputa na sociedade contemporânea, sendo elementos importantes para a construção de projetos societários. Por isso, é fundamental tensionar essa discussão, principalmente refletindo sobre as diversas concepções e posicionamentos que fundamentam o processo educacional.

O município de Itaboraí, localizado no estado do Rio de Janeiro, no ano de 2012, iniciou um movimento denominado reorientação curricular no qual todos os segmentos e modalidades precisavam participar e repensar o seu "currículo". Esse movimento deu origem à construção de um documento chamado de versão preliminar e que foi revisado após experimentação nas unidades escolares, como projeto piloto no ano de 2013. Trata-se de um processo complexo que implica no embate de diferentes instâncias e concepções teóricas.

As recentes políticas de currículo elaboradas para esta modalidade são um marco importante para a construção de referenciais específicos para a EJA. Porém, não podemos desconsiderar que as políticas estão em consonância com o tipo de sociedade que se deseja constituir. Por isso, optamos por analisar as políticas de currículo nos espaços formais de educação, especificamente o currículo que é praticado para a EJA na rede municipal de ensino de Itaboraí, fazendo um contraponto com o movimento iniciado pelo governo federal para a construção da Base Nacional Comum Curricular (BNCC).

Conforme Santos (2008), analisar as políticas de currículo e as práticas curriculares que estão em voga no sistema educacional nos auxiliam na com-

${ }^{*}$ DOI - 10.29388/978-65-86678-41-3-0-f.95-110

1 Pedagoga, Especialista em Educação de Jovens e Adultos, Mestre em Educação pela Universidade Federal Fluminense e Doutoranda em Educação pela Universidade do Estado do Rio de Janeiro. Assessora Pedagógica da Educação de Jovens e Adultos da Secretaria Municipal de Educação de Itaboraí e Professora do Núcleo de Educação de Adultos do Departamento de Educação da Pontifícia Universidade Católica do Rio de Janeiro. Membro do Colegiado do Fórum EJA- RJ. 
preensão dos avanços e dos retrocessos para a educação de jovens e adultos no Brasil. As iniciativas do poder público, segundo este autor, têm se apropriado das políticas curriculares para instituir concepções de educação e sociedade. Tais iniciativas objetivam controlar e induzir as propostas curriculares nas instituições de ensino brasileiras.

Mas as políticas de currículo não são instituídas apenas pelo Estado, a partir de um movimento de cima para baixo, cabendo ainda a cada ente federado e as instituições de ensino executá-las e ressignificá-las. Por isso, compreendendo a sua complexidade, a pesquisa de dissertação de mestrado, defendida em 2016, que possibilitou a escrita deste artigo, teve como objetivo principal analisar, após o movimento de Orientação Curricular iniciado pela Secretaria Municipal de Educação e Cultura de Itaboraí - Rio de Janeiro (SEMEC) em 2012, o currículo de educação de jovens e adultos (EJA).

Para realização deste trabalho, dialogamos com diversos autores, concepções e com os mais distintos conceitos que nos auxiliaram na compreensão daquilo que os sujeitos trouxeram como contribuições para pensar currículo da EJA.

Buscando compreender como os sujeitos da EJA em Itaboraí percebem o currículo no cotidiano escolar, utilizamos como estratégia de pesquisa o grupo de discussão para reflexão do tema.

Segundo Dubet (1994, p. 105),

O grupo de discussão parece responder a algumas das finalidades da sociologia da experiência, pois considera cada indivíduo como um intelectual, como um ator capaz de dominar conscientemente, numa certa medida, a sua relação com o mundo.

Como característica do grupo de discussão, essa interação/conversação não tem o objetivo de chegar a um consenso entre os envolvidos, mas analisar as percepções dos sujeitos sobre o tema proposto. Ou seja, em síntese, adaptase melhor ao estudo de fenômenos sociais do cotidiano, possibilitando recolher um leque de opiniões e pontos de vista sobre o tema (Callejo, 2001).

Considerando que o currículo é uma variável que pode explicar os impasses e os conflitos vivenciados no cotidiano escolar, procuramos refletir sobre o processo de construção do currículo de EJA no município de Itaboraí.

O diálogo com os sujeitos da pesquisa, em linhas gerais, possibilitou identificar que a flexibilidade e a diversidade são pontos fundamentais para a construção de um currículo que atenda as especificidades da EJA. 
Reconhecendo as limitações da pesquisa, esperamos que este artigo seja uma contribuição para ampliação das discussões no campo da educação de jovens e adultos.

\section{A construção dos Referenciais Curriculares na rede municipal de ensino de Itaboraí}

O processo de construção dos Referenciais Curriculares será descrito com base nos relatórios produzidos pela Secretaria Municipal de Educação e Cultura (SEMEC) e pelas observações realizadas pela pesquisadora como assessora pedagógica da EJA neste período.

Considerando que os Referenciais Curriculares evidenciados no Projeto Político e Pedagógico (PPP) de 2003 não atendiam mais as necessidades da educação pública municipal, desde 2009, a SEMEC almejava construir um documento para nortear o currículo da rede municipal de ensino. Após diversas tentativas de parceria malfadadas com instituições públicas e privadas de ensino superior, no ano de 2012, os próprios funcionários da Subsecretaria Municipal de Ensino assumiram para si a tarefa de repensar o currículo.

A comissão foi composta por profissionais que atuavam nas coordenações de educação especial, de EJA, de educação infantil, de ensino fundamental I, de ensino fundamental II, de educação integral e da coordenação da equipe técnico-pedagógica. Do grupo, dois profissionais ficaram responsáveis por coordenar este processo que contava com a participação de 35 pessoas ao todo.

A equipe era composta por profissionais das mais variadas formações acadêmicas e possuíam concepções e visões de mundos distintas. Por isso, como uma primeira estratégia, foram organizados estudos dirigidos sobre currículo para discutir o campo e assumir uma diretriz teórica.

O quadro teórico foi baseado nas principais questões apresentadas por Silva (1999), assim como em autores representativos do campo do currículo. Além das legislações vigentes, foram analisados: o Marco Referencial do Projeto Político e Pedagógico da rede de Itaboraí - 2003; a Resolução do Conselho Nacional de Educação no 4 de 13/07/2010 que define as Diretrizes Curriculares Nacionais Gerais para a Educação Básica; a Resolução do Conselho Nacional de Educação n 7 de 14/12/2010, que fixa as Diretrizes Curriculares Nacionais para o Ensino Fundamental de 9 anos; a Resolução do Conselho Nacional de Educação no $1 / 2000$ que organiza as Diretrizes Curriculares Nacionais para a Educação de Jovens e Adultos; e a Resolução do Conselho Nacional de Edu- 
cação no 3/2010 que apresentam as Diretrizes Operacionais para a Educação de Jovens e Adultos nos aspectos relativos à duração dos cursos e idade mínima para ingresso nos cursos de EJA, a idade mínima e certificação nos exames de EJA e Educação de Jovens e Adultos desenvolvida por meio da Educação a Distância.

As discussões tecidas pelo grupo permitiram compreender os conflitos e as disputas presentes na produção de políticas de currículo.

Foram inúmeros encontros com circularidade de saberes, tornando-se um momento rico de troca de ideias. Com isso, nesta arena de disputas, os estudos nos permitiram enfrentar os embates com maior propriedade e argumentos para defendermos nossos pontos de vista (ITABORAÍ, 2012e, p. 2).

Após este primeiro momento de discussão coletiva entre os membros da Subsecretaria de Ensino, o grupo definiu que o currículo seria entendido como "conjunto de valores e práticas que proporcionam a produção, a socialização de significados no espaço social e contribuem intensamente para a construção de identidades socioculturais dos educandos e para a transformação social" (ITABORAÍ, 2012e, p. 4).

A comissão também definiu que o documento formal deveria ser orientado por expectativas de aprendizagem, eixos temáticos e orientações metodológicas, sendo construído um referencial curricular para cada etapa e modalidade da educação básica.

Considerando que o trabalho deveria ser aberto a contribuições, a comissão assumiu que as discussões levariam em consideração a opinião dos seus técnicos, de professores universitários (através de palestras e textos publicados) e dos professores de todas as escolas da rede municipal de ensino.

Levando em consideração os referenciais produzidos e a adesão do documento pelos profissionais da rede municipal de ensino, a SEMEC institui uma política de formação continuada que, em tese, deveria ser realizada periodicamente por todas as coordenações da Subsecretaria de Ensino.

A partir da análise do movimento iniciado por Itaboraí, podemos identificar que o currículo foi produzido no contexto das relações de poder. Houve uma necessidade dos técnicos da SEMEC em reformulá-lo, porém, não podemos desconsiderar que houve uma tentativa de torná-lo democrático a partir da inclusão de professores que estavam atuando em sala de aula e a partir das dis- 
cussões realizadas nos fóruns e debates. Lamentavelmente, a experiência só não ouviu os seus alunos no processo de produção do documento.

Notamos na análise da produção dos Referenciais Curriculares de Itaboraí que mais importante do que mensurar quais conteúdos iriam ou não nortear o currículo, o movimento de discussão proposto pelo município possibilitou que os sujeitos pudessem discutir as concepções que norteariam o documento, provocando embates, consensos e discordâncias, sendo esta a parte mais interessante do movimento organizado por Itaboraí.

Desconsiderar conflitos e antagonismos nas políticas de currículo parece-nos ainda mais limitador, na medida em que implica desconsiderar as especificidades dessas políticas na produção da cultura (Hall, 2003 apud LOPES; DIAS; ABREU, 2011, p. 28).

Infelizmente, nem todas as vozes foram ouvidas durante este processo, principalmente as dos alunos. Em relação à EJA, este fato contraria a valorização das experiências dos sujeitos da EJA no processo educacional. Repensar as políticas curriculares neste contexto torna-se fundamental para esta modalidade de ensino, pois o compromisso das esferas governamentais com a EJA ainda está aquém do que deveria, tornando-se importante problematizar os seus sentidos e desafios a partir do constante diálogo entre os envolvidos, respeitando os seus desejos, interesses e a diversidade do público-alvo.

No processo realizado por Itaboraí, foi possível ainda perceber ênfase na construção de um documento formal e prescrito. Porém, por outro lado, defendendo uma ideia de referencial, o documento também, em tese, atribui à es cola um importante papel na reconfiguração do currículo, diferente da proposta da Base Nacional Comum Curricular (BNCC), por considerar que a Base pode homogeneizar o currículo, contrariando as discussões e as pesquisas realizadas no campo do currículo que valorizam as políticas de diversidade.

\section{Currículo pautado em uma base nacional comum}

De acordo com Macedo (2014, p. 1532), não são recentes os discursos que defendem a construção de um currículo pautado em uma base nacional comum, pois a LDB (Lei 9394/1996), no artigo 21, já mencionava a necessidade de construção de um documento construído em escala nacional. "A defesa de uma base nacional comum para o currículo tem funcionado como uma das muitas promessas de dar qualidade à educação para diferentes grupos da sociedade". 
Para atender a estes anseios, foram criados logo após a Lei de Diretrizes e Bases da Educação Nacional - LDB, os Parâmetros Curriculares Nacionais (PCN). Contudo, uma parte da comunidade acadêmica brasileira denunciou que a elaboração deste documento atendia apenas os interesses e as exigências de cunho neoliberal propostas pelo Banco Mundial, cujo objetivo era apenas centralizar e monopolizar os sentidos educacionais para atender os interesses do capital. Desta forma, o Ministério da Educação (MEC), após receber diversas críticas, optou por considerar o documento como referência/alternativa curricular não obrigatória.

É fundamental levar em conta que os PCN também foram construídos com a participação de especialistas e professores universitários, sendo assim, não podemos afirmar que havia consenso em relação a não aceitação do documento por parte da comunidade acadêmica.

A nova configuração política estabelecida no país a partir de 2003 não esvaziou a discussão em relação à construção de um documento nacional comum curricular, apenas houve uma nova articulação no sentido de incluir e garantir a participação de grupos que até então haviam sido excluídos deste processo, tendo papel fundante a então Secretaria de Educação Continuada, Alfabetização, Diversidade do Ministério da Educação (SECAD/MEC), que passou a lutar pela incorporação da diversidade dos sujeitos nas políticas curriculares.

As mudanças e os novos arranjos políticos não romperam com a ideia de centralização curricular para garantir a qualidade social da educação. Ao contrário, continuaram sendo favoráveis a estas políticas "movida por interesses diversos, a rede de agentes políticos públicos e privados luta por fixar sentidos para um clamor universal, que ela também constrói, por educação de qualidade" (MACEDO, 2014, p. 1534).

No ano de 2009, o MEC, com a participação de inúmeros especialistas no assunto e membros da comunidade acadêmica, retomou a discussão e lançou o Programa Currículo em Movimento, objetivando atualizar as Diretrizes Curriculares Nacionais, propostas para todos os níveis e modalidades de ensino, assegurando uma formação básica comum para todos os alunos.

Em 2014, após a aprovação do Plano Nacional de Educação (PNE) é reiterada a importância de um documento comum nacional. O PNE faz uma distinção entre Diretrizes Curriculares Nacionais (DCN) e Base Nacional Comum Curricular (BNCC). Ou seja, retira o caráter de referência e/ou alternativa curricular e incorpora o sentido de obrigatoriedade de aplicação do documento, 
destinando apenas $40 \%$ deste para a inclusão das especificidades locais/regionais.

Desta maneira, para atender o que havia sido proposto pelo PNE, em 2014, o MEC lançou uma versão inicial do que seria a BNCC, sendo esta construída por equipes formadas pela Secretaria Nacional de Educação Básica. Após esse movimento inicial, o MEC disponibilizou o documento em um portal na internet, sugerindo que este fosse amplamente discutido antes da sua versão final em 2016.

Para Cunha (2015, p. 538), a ideia de uma base nacional comum é construída a partir da afirmação de que todos têm o direito de aprender aquilo que é considerado pela sociedade como necessário à escolarização básica dos alunos. Desta maneira, o MEC justifica a importância da construção deste documento, considerando ser fundamental garantir menos disparidades em relação ao processo de ensino e aprendizagem dos estudantes de todo o Brasil, chamando esse processo de direito à aprendizagem.

Instituições que representam diversos segmentos da comunidade acadêmica, como a Associação Nacional de Pós-graduação e Pesquisa em Educação (ANPED) e a Associação Nacional de História (ANPUH), emitiram parecer ao Conselho Nacional de Educação (CNE) questionando o processo de construção do documento e sua respectiva representatividade.

O que nos chama atenção é que estas instituições diferem no seu posicionamento político. A carta emitida pela ANPUH, por exemplo, não questiona a construção de um documento de base nacional comum curricular, levandonos a entender que a instituição apoia este processo. Segundo a ANPUH (2016, p. 2), "reafirmamos que os problemas apresentados neste documento visam, unicamente, colaborar para o aprimoramento da proposta".

Os questionamentos da ANPUH levam em consideração alguns princípios: falta de clareza em relação às escolhas de alguns conteúdos em detrimentos de outros; formulação equivocada de alguns conceitos; falta de concatenação em relação aos objetivos da aprendizagem aos longos dos anos; ausência de uma reflexão crítica em relação ao conhecimento histórico e falta de transparência na escolha dos membros que foram responsáveis pela elaboração da versão inicial do documento (ANPUH, 2016, p. 2).

Já a ANPED afirma que a construção de uma base nacional comum curricular prevê a uniformização dos conhecimentos através de uma administração centralizada, não levando em consideração as especificidades de cada região/escola/estudante, eliminando suas diferenças. Tal uniformização elimina as 
possibilidades de flexibilização curricular, sendo algo apontado como intrínseco a um projeto de sociedade democrática, afirmando que o documento orientador da BNCC é uma "descaracterização do estudante em sua condição de diferença, bem como da desumanização do trabalho docente em sua condição criativa e desconsideração da complexidade da vida na escola" (ANPED, 2016, p. 2).

O documento explicita nove motivos pelos quais a BNCC deve ser desconsiderada: diversidade versus uniformização; nacional como homogêneo: um perigo para democracia; os entendimentos do Direito à Aprendizagem; conteúdo não é base; o que não se diz sobre as experiências internacionais; gestão democrática versus responsabilização; a Base e a avaliação; desqualificação do trabalho docente: unificação curricular e avaliação externa; e metodologia da construção da Base: pressa, indicação e indefinição.

Segundo a ANPED, o direito à aprendizagem só pode ocorrer concomitantemente com o direito à diferença e a pluralidade e não através de um currículo mínimo que apenas objetiva controlar e uniformizar os conteúdos e os saberes que deverão nortear o fazer pedagógico nas unidades escolares de todo o país. O documento é tratado apenas como uma lista de conteúdos a serem aplicados nas escolas, desvalorizando a autonomia dos sujeitos no processo educacional e a conversão do direito de aprender dos estudantes através de um processo dialógico, social e democrático.

Ainda de acordo com a ANPED, o MEC, a partir de um processo contínuo, está silenciando os debates, avanços e as políticas de currículo que atuam na perspectiva da diversidade. Sendo assim, o movimento do MEC está coerente com o projeto mercadológico e as tendências internacionais que visam apenas padronizar e centralizar o currículo, sendo este constantemente avaliado a partir de modelos uniformes e hierarquizantes, baseados em avaliações externas e aplicados em escala nacional, a partir de políticas neoliberais. Desta maneira, os resultados "negativos" serão considerados como responsabilidade dos gestores locais e dos professores através de uma concepção de meritocracia.

A carta emitida por esta instituição também questiona a metodologia empregada pela BNCC na construção do documento, pois considera que existe pouca definição sobre as etapas e os critérios adotados, sendo estes guiados pela pressa, gerando pouco debate e participação efetiva dos sujeitos que constroem o currículo nos espaços escolares: professores e estudantes.

Outro aspecto defendido é o fato de já existirem experiências curriculares construídas ao longo da história nas escolas brasileiras e as singularidades de cada local/escola não podem ser vistas ou incorporadas apenas como parte di- 
versificada, pois o currículo não pode ser separado, não existindo essa dissociação do que seria currículo mínimo e currículo diversificado, como proposto pela BNCC.

Cunha $(2015$, p. 580) alerta para o fato de que existe neste processo uma tentativa de fixação de um determinado recorte cultural, em detrimento de tantos outros possíveis, e de uma identidade que se almeja formar na escola a partir de construção de determinadas narrativas/discursos, explicitando a relação de poder/dominação que está em jogo no sistema educacional.

Macedo (2014, p. 1553) acrescenta que:

É preciso seguir lembrando que um currículo nacional não vai melhorar a educação nem garantir desenvolvimento e melhor distribuição de renda. O que ele tem a oferecer é apenas a tentativa de controle do imponderável da qual depende, não o sucesso da educação, mas a hegemonia do imaginário neoliberal de que ele é parte.

Destacamos que a EJA não foi incorporada na elaboração da BNCC. Podemos considerar que, independente do processo que a construção deste documento esteja gestando, a ausência da EJA pode estar vinculada ao fato da modalidade de ensino ainda ser vista com menos prestígio pelo MEC, não carecendo neste momento entrar na pauta das políticas curriculares nacionais.

Infelizmente, o movimento iniciado pelo MEC desconsidera as particularidades de cada região do país e das políticas de currículo já construídas pelas redes de ensino e unidades escolares, conforme ocorrido em Itaboraí.

\section{Currículo: a flexibilidade como aspecto fundamental}

Diferentemente do que é proposto pela BNCC, os professores de Itaboraí que participaram da pesquisa e do processo de construção dos Referenciais Curriculares da rede municipal de ensino, sinalizaram que em relação às concepções de currículo, a autonomia do professor precisa ser respeitada no cotidiano escolar, assim como a flexibilidade para a construção de práticas curriculares que atendam as especificidades da EJA.

Os conteúdos não podem ser simplesmente depositados nos alunos, pois eles precisam ser ressignificados/modificados de acordo com cada contexto, a partir do contato do professor com a diversidade dos estudantes, suas trajetórias de vida e as experiências trazidas por estes sujeitos para o contexto de 
escolarização. Ou seja, respeitar as múltiplas dimensões do currículo, que estão para além de conteúdos prescritos e listados.

Os professores da EJA também reconhecem a necessidade de incorporar processos mais democráticos na construção do currículo, respeitando os anseios/desejos dos alunos, baseados nos princípios da Educação Popular e na perspectiva da diversidade e do mundo do trabalho.

Os professores destacaram a importância do movimento iniciado em Itaboraí no ano de 2012, pois, segundo eles, não há problemas em sistematizar os conhecimentos que deverão nortear o ensino na rede municipal, sendo fundamental a construção de um documento norteador para a EJA que não esteja à mercê do ensino regular. Contudo, este deve ser visto apenas como uma referência de trabalho, sofrendo adaptações de acordo com as características de cada turma/aluno.

Currículo não envolve só os referenciais. Referenciais é apenas um aspecto do currículo. Currículo é um todo, dentro da comunidade escolar, envolvendo diversas dimensões e toda a comunidade escolar. São vários aspectos que vão construir esse currículo (Professor do Ensino Fundamental II (SILVA, 2016, p. 104).

Percebemos que os professores possuem perspectivas de currículo que vão para além das práticas tradicionais, não sendo visto como algo neutro e traduzido apenas nos documentos formais. Os professores consideram outras dimensões, tais como: experiências extraescolares, as relações estabelecidas entre os sujeitos no cotidiano escolar, perfil dos alunos, entre outros.

É possível notar que compreendem a existência de uma concepção de currículo manifesto e de currículo oculto. Ambos caminham juntos no tempo/ espaço escolar. Ou seja, compreendem que a escola além de desenvolver o currículo explícito, que está formalizado no projeto político pedagógico, em suas matrizes curriculares, em suma, aquele que é tido como oficial, desenvolvem também o que podemos chamar de currículo oculto, referente à transmissão de valores, normas e comportamentos.

A flexibilidade é enfatizada a todo o momento pelos professores que fizeram parte da pesquisa, sendo considerada como algo fundamental, pois possibilita modificar as práticas pedagógicas para alcançar os objetivos almejados a partir das reflexões em relação aos avanços e retrocessos dos alunos. Para os professores não significa abolir por completo os referenciais, mas resignificá-los de acordo com as demandas do cotidiano. 
Para os professores, currículo não significa apenas transmitir conhecimentos, mas dar contas de outras demandas, entre elas fortalecer a autoestima dos alunos e prestigiar as suas experiências de vida.

O currículo ideal não é aquele currículo engessado. O currículo ideal seria aquele currículo que tivesse sempre um desdobramento (Professora do Ensino Fundamental II (SILVA, 2016, p. 105).

A partir das questões tecidas nos grupos de discussão da pesquisa, percebemos que os professores não negam a importância de um referencial curricular comum organizado em rede. Contudo, ressaltam a importância da flexibilidade, sendo esta fundamental para atender as necessidades da EJA, o que difere da proposta da BNCC.

\section{Políticas de Diversidade}

$\mathrm{Na}$ análise do material empírico desta pesquisa foi possível observar que, em relação às concepções de EJA, os sujeitos percebem que esta modalidade precisa garantir uma educação permanente, comprometida com a qualidade e a ampliação do universo cultural dos estudantes, principalmente a partir de uma perspectiva crítica, almejando transformação da realidade socioeconômica dos sujeitos alunos. Mas para isso, é necessário reconhecer a diversidade que representam estes sujeitos e saber lidar com elas no cotidiano escolar, principalmente a diversidade etária/geracional, assim como de etnia/raça e de gênero, visto que compreendem o público majoritário desta modalidade de ensino.

De acordo com os professores, além do aspecto burocrático, o currículo precisa abarcar a diversidade do público-alvo desta modalidade de ensino, através do reconhecimento da diversidade dos sujeitos, pois o contrário pode gerar novas exclusões sociais por não atender as necessidades dos alunos.

Essa diversidade de formas é a diversidade da EJA. Tenho alunos que têm um grau de conhecimento diferenciado, apesar de estarem na mesma fase. Alunos muito novos e alunos idosos. Então como conciliar toda essa diversidade? O currículo da EJA tem que ter uma capacidade de lidar com essa diversidade. (Professora do Ensino Fundamental II (SILVA, 2016, p. 106). 
Outro aspecto importante apontado pelos grupos de discussão é o descompasso em relação à falta de articulação entre os alunos jovens, adultos e idosos. A escola ainda não encontrou um ponto de equilíbrio na convivência destes sujeitos. De acordo com eles, a convivência intergeracional pode ser muito proveitosa, mas para isso a escola precisa saber lidar com as necessidades de cada público, promovendo de fato uma interlocução entre os estudantes.

A questão da juvenilização nesta modalidade de ensino não é algo recorrente apenas em Itaboraí, mas em todo território nacional. Podemos sinalizar vários motivos que estão ocasionando a mudança de perfil dos alunos desta modalidade de ensino, especificamente nas turmas do Ensino Fundamental II (VI a IX fases). Dentre eles, destacamos que a EJA ainda é vista pelos profissionais que atuam no Ensino Regular como depósito dos alunos indisciplinados e portadores de deficiência, necessitando maior diálogo com este segmento.

Desta maneira, a EJA é vista apenas como correção de fluxo, tendo como propósito atender os excluídos do Ensino Regular. Tal concepção é reforçada pela legislação vigente, conforme previsto na Resolução do Conselho Nacional de Educação n ${ }^{\circ}$ 3/2010 que apresentam as Diretrizes Operacionais para a Educação de Jovens e Adultos nos aspectos relativos à duração dos cursos e idade mínima para ingresso nos cursos de EJA, a idade mínima e certificação nos exames de EJA e Educação de Jovens e Adultos desenvolvida por meio da Educação a Distância. O documento destina um parágrafo específico para incentivar as redes de ensino a migrarem os alunos na faixa etária de 15 a 17 anos para a EJA, no intuito de acelerarem os seus estudos.

Com isso, esses jovens são transferidos, muitas vezes, de forma compulsória para a EJA sem o desenvolvimento de um trabalho específico para atender as suas singularidades.

Para enfrentar o desafio disso que temos chamado de "juvenilização da EJA", deveríamos caminhar para a produção de espaços escolares culturalmente significativos para uma multiplicidade de sujeitos jovens - e não apenas alunos - histórica e territorialmente situados e impossíveis de conhecer a partir de definições gerais e abstratas. Neste sentido, seria preciso abandonar toda a pretensão de elaboração de conteúdos únicos e arquiteturas curriculares rigidamente estabelecidas para os "jovens da EJA" (CARRANO, 2007, p. 58).

Nesse sentido, é fundamental reforçar que a EJA não deve estar atrelada à simples correção de fluxo e a simples certificação dos estudantes. Precisa- 
mos investir em propostas que visem respeitar a EJA enquanto modalidade da Educação Básica e não apenas como depósito das insuficiências do Ensino Regular, promovendo melhorias significativas neste segmento.

A diversidade precisa nortear o currículo da EJA, pois só existe diálogo quando o outro é reconhecido como sujeito de direitos, independente da etnia, opção sexual, religiosa, entre outros. Com isso, o currículo precisa estimular a reflexão em torno dos direitos humanos fundamentais e a criticidade da sociedade desigual e excludente que estamos inseridos, identificando que os discursos em torno da diferença são construídos para dotar alguns sujeitos de poder em detrimentos de outros.

As materializações das diversas identidades nas turmas de EJA tornam este espaço heterogêneo e complexo, demandando análises que deverão estar associadas a outros fatores e contextos de cunho social, político e econômico.

É fundamental neste processo respeitar o perfil e a diversidade dos alunos da EJA, pois o contrário pode fazer com que esses alunos não se identifiquem com a escola, justificando a evasão e a diminuição de matrículas. Ficando claro que o currículo contribui como formador de identidades.

Portanto, é fundamental garantir que o currículo da EJA valorize as experiências, as vozes e os diversos espaços que circulam os sujeitos jovens e adultos, articulando a formação básica com a participação no mundo do trabalho e na perspectiva da diversidade, estabelecendo inter-relações entre teoria e prática, nos eixos da ciência, do trabalho e da cultura, de forma a organizar o tempo e os espaços pedagógicos adequados às especificidades desses estudantes, respeitando as manifestações culturais e o direito de acesso a toda cultura, arte e ciência produzida historicamente pela sociedade.

\section{Referências}

ANPED. Exposição de Motivos a BNCC. Rio de Janeiro. 2015. Acesso em 10 de março de 2016. <http://ced.ufsc.br/files/2015/10/Exposi $\% \mathrm{C} 3 \% \mathrm{~A} 7 \% \mathrm{C} 3 \%$ A3o-de-Motivos-a-BNCC-ANPED-e-ABdC.pdf $>$ Acesso em: 25 out. 2020.

BRASIL. Ministério da Educação - Conselho Nacional de Educação. Parecer CNE/CEB 11/2000. Institui as Diretrizes Curriculares Nacionais para a Educação de Jovens e EJA. 2000a - Ministério da Educação - Conselho Nacional de Educação. Parecer CNE/CEB n 6 de 07 de abril de 2010. Reexame do Parecer CNE/CEB n ${ }^{\circ}$ 
23/2008. Diário Oficial da União, Brasília, DF, 09 de junho de 2010, Seção 1, Pág.20. 2010b

. Ministério da Educação - Conselho Nacional de Educação. Resolução do Conselho Nacional de Educação no 4 de 13/07/2010. Define as Diretrizes Curriculares Nacionais Gerais para a Educação Básica. Diário Oficial da União, Brasília, 14 de julho de 2010, Seção 1, p. 824.

. Ministério da Educação - Conselho Nacional de Educação. Resolução do Conselho Nacional de Educação $n^{\circ} 7$ de 14/12/2010. Fixa as Diretrizes Curriculares Nacionais para o Ensino Fundamental de 9 anos. Diário Oficial da União, Brasília, 15 de dezembro de 2010, Seção 1, p. 34.

. Ministério da Educação - Conselho Nacional de Educação/ Câmara de Educação Básica. Resolução no 3 de 15 de julho de 2010. Institui Diretrizes Operacionais para a Educação de Jovens e Adultos nos aspectos relativos à duração dos cursos e idade mínima para ingresso nos cursos de EJA; idade mínima e certificação nos exames de EJA; e Educação de Jovens e Adultos desenvolvida por meio da Educação a Distância. Diário Oficial da União, Brasília, 16 de julho de 2010, Seção 1, p.66.

. Presidência da República - Casa Civil, Subchefia para Assuntos Jurídicos. Lei $\mathbf{n}^{\mathbf{0}} \mathbf{1 1 . 2 7 4}$, de $\mathbf{6}$ de fevereiro de 2006. Altera a redação dos arts. 29, 30, 32 e 87 da Lei no 9.394, de 20 de dezembro de 1996, que estabelece as diretrizes e bases da educação nacional, dispondo sobre a duração de 9 (nove) anos para o ensino fundamental, com matrícula obrigatória a partir dos 6 (seis) anos de idade.

CALLEJO, J. El grupo de discusión: introducción a una práctica de investigación. Barcelona: Editorial Ariel. 2001

CARRANO, P. C. R. Educação de Jovens e Adultos e Juventude: o desafio de compreender os sentidos da presença dos jovens na escola da "segunda chance”. REVEJ@ - Revista de Educação de Jovens e Adultos, v. 1, n. 0, p. 1-108, ago. 2007.

CUNHA, Érika Virgílio Rodrigues da. Cultura, contexto e a impossibilidade de uma unidade essencial para o currículo. Currículo sem Fronteiras, v. 15, n. 3, p. 575-587, set./dez. 2015.

DUBET François. Sociologie de l'expérience. Éditions du Seuil. Paris, SE, 1994. 
ITABORAÍ. Projeto Político Pedagógico. Itaboraí: SEMEC, 2003.

Referenciais Curriculares. Itaboraí: SEMEC, 2012.

LOPES, A. C.; DIAS, R. E.; ABREU, R. G. de. (Org.) Discursos nas políticas de currículo. Rio de Janeiro: Quartet, 2011.

MACEDO, E. Currículo como espaço-tempo de fronteira cultural. Revista

Brasileira de Educação, São Paulo, v. 11, n. 32, p. 285-296, 2014.

MACHADO, Maria Margarida. A educação de jovens e adultos no Brasil pósLei $n^{\circ}$ 9.394/96: a possibilidade de constituir-se como política pública. In: MACHADO, Maria Margarida (org.). Educação de Jovens e Adultos. Em Aberto / Instituto Nacional de Estudos e Pesquisas Educacionais Anísio Teixeira. v. 1, n. 1. Brasília: INEP, 2009.

SANTOS, J. Ê. S. Educação Geográfica de Jovens e Adultos Trabalhadores: Concepções, Políticas e Propostas Curriculares. 2008, f 201. Tese de Doutorado (Educação) - Programa de Pós-graduação em Educação, Universidade Federal Fluminense, Niterói, 2008.

SILVA, A. B. da. O currículo na educação de jovens e adultos: análise da experiência do município de Itaboraí. 2016 f. 176. Dissertação Mestrado (Educação) - Programa de Pós-graduação em Educação, Universidade Federal Fluminense, Niterói, 2016.

SILVA, T. Tadeu. Documentos de identidade. Belo Horizonte: Autêntica, 1999. 
